\title{
Statistics of Indian earthquakes - Frequency energy distribution
}

\author{
R. K. S. Cimouhan $\left({ }^{*}\right)-$ V. K. Shrivastaya $\left({ }^{* *}\right)$
}

Received on December 20th, 1973

\begin{abstract}
Sumary. - Frequency-magnitude and energy-magnitude distribution of the Indian earthquakes have been studied for both shallow and intermediate earthquakes using data from 1910 to 1969 . Secular energy released by the Indian earthquakes has been studied by considering cumulative energy release and it is found that these results may be used to estimate the size of largest conceivable earthquakes for shallow and intermediate focal depths.
\end{abstract}

Riassunto. - Dai dati reperiti dal 1910 al 1969 , è stata studiata la distribuzione della frequenza-magnitudo e dell'energia-magnitudo di terremoti a carattere superficiale e intermedio avvenuti in India, nonché l'energia secolare liberata da questi ultimi considerando l'energia totale liberata. Si e trovato che questi risultati possono essere usati per valutare l'intensità, per quanto grande essa possa essere, di terremoti a fuoco superficiale e intermedio.

\section{1. - INTRODUCTION}

Gutenberg and Richter in their monumental work "Seismicity of the Earth and associated phenomena" (5) have shown that the rate of energy released by earthquakes is extremely irregular for the whole world. The single year 1906 accounts for about one ninth of the global energy release, so that the average annual release between 1907-1952

(*) Department of Geophysies, Indian School of Mines, Dhanbad826004 , India.

(**) Department of Geophysies, Banaras Hindu University, Varanasi-5, India. 
is only $11.0 \times 10^{26}$ ergs while the average between $1906-1952$ is $12.4 \times 10^{26}$ ergs, using energy magnitude relation

$$
\log E=12.0+1.8 M
$$

where $E$ is the energy in ergs and $M$ is the Richter's magnitude.

Intermerliate shocks show that the maximum energy was released in 1910 and 1911 owing to two large earthquakes in these years.

The ratio of average annual energy release in shallow, intermerliate and deep earthquakes is 31:4:1 according to Gutenberg and Richter $\left(^{5}\right)$. But in the year 1920 this ratio was $265: 2: 1$ i.e. about $98 \%$ of the entire energy released in shallow earthquakes. Similarly in the year 1969 , Chouhan and Das $\left({ }^{3}\right)$ reporter that about $98 \%$ of the energy was releaser by shallow earthquakes.

The energy released in different magnitude ranges for shallow, intermerliate and deep shocks is found to decrease with the value of magnitude.

The number of shocks decreases with depth. According to Gutenberg and Richter $\left(^{5}\right)$ the number of shocks rlecreases to a minimum at a depth of about $450 \mathrm{~km}$, there being a clear rise to a minor maximum at a depth of about $600 \mathrm{~km}$, beyond which the number falls off very rapidly. Ritsema ( $\left.{ }^{8}\right)$ while considering the distribution of intermerliate and rleep shocks of varying magniturles with depth, found that the curves showing variation of earthquake number show maxima at depths of 80 to $90 \mathrm{kms}$ and 220 to $280 \mathrm{kms}$ with a minor maxima at a rlepth of about $180 \mathrm{kms}$. These general results can be confirmerl by use of small agreegate numbers in the range of times and magniturles considered statistically. Thus, there is no general agreement on the distribution of earthquakes with depth, however, these results are expected to be different in different geographic regions of the world.

\section{2. - OBshritonal Data}

For the frequency-energy distribution of shallow and intermediate earthquakes of India, the data has been extracted from Gutenberg and Richter $\left(^{5}\right)$, Seismological Bulletins of India Meteorological Department, I.S.S. bulletins and U.S.C.G.S. bulletins in arldition to other sources; the span of time being sixty years (from 1910 to 1969). The magniturles used here are all Richter's magnitudes $M \geqslant \check{\text { o }}$ 
For calculations of energy from the magnitude values $M$, the following relation of Gutenberg and Richter $\left(^{6}\right)$ have been used.

$$
\log E=A+B M
$$

where $A=11.8$ and $B=1.5$.

\section{3. - Frequency-Energy Distribution}

Annual frequencies of all the earthquakes of different magnitudes $M$ in the range of 5 to 8.6 have been calculated using all the earthquakes that have occurred since 1910 ; for magnitudes 5 to 5.2 the time span is 13 years. Thus, the frequencies of shallow $\left(N_{s}\right)$ and intermediate earthquakes $\left(N_{i}\right)$ have been determined and given in Table 1. Annual energy released by shallow $\left(E_{s}\right)$ and intermediate $\left(E_{i}\right)$ earthquakes of different magnitudes has been calculated using equation [2] and is also tabulated in Table 1.

Figures 1 and 2 show the frequency-energy distribution of earthquakes against magnitude, the general shape of the figures being approximately parallelogram defining the boundaries of the frequency and energy of different magnitudes in the range of 5.0 to 8.6 . These figures clearly show that the frequency of earthquakes is maximum when the energy release is minimum or vice versa, a well known fact in earthquake seismology. In seismology these facts are expressed by representing logarithmic dependence of $E$ the seismic energy and $N$ the earthquake frequency, on magnitude $\boldsymbol{M}$. These relations are known as energy-magnitude (Eq. 2) and frequency-magnitude relations as given by Gutenberg and Richter $\left.{ }^{5}\right)$ in the form

$$
\log N=a-b M
$$

where $a$ and $b$ are constants.

However in the present analysis the energy magnitude relation has been assumed logarithmic and then the energy values are calculated as given in the Table 1 . The slope of the two sides of the approximate parallelogram (not shown in the figures 1 and 2) may take any shape depending upon the values of $B$ and $b$. It has been observed by Utsu $\left({ }^{10}\right)$, Chouhan $\left({ }^{4}\right)$, Page $\left({ }^{7}\right)$ that the value of $b$ varies from 0.4 to 1.5 and Bath (1) has also shown that the value of $B$ may be taken as 1.44 also, apart from Gutenberg-Richter's value of 1.5 . Thus we can say that the slope of $E$ changes from 1.44 to 1.50 while 


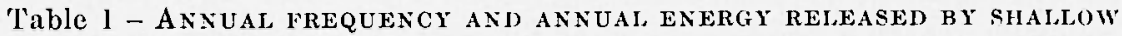
AND INTERMEDIATE EARTHQUAKES OF DIFFERENT MAGNITUDES DURING TILE PERIOD 1910 TO 1969 WITII $M \geqslant 5$.

\begin{tabular}{|c|c|c|c|c|}
\hline \multicolumn{2}{|c|}{$\begin{array}{c}\text { Annual frequency of } \\
\text { earthquakes }\end{array}$} & \multirow{2}{*}{$\begin{array}{l}\text { Magrnitude } \\
(M)\end{array}$} & \multicolumn{2}{|c|}{$\begin{array}{l}\text { Annual energy released by } \\
\text { earthquakes }\left(\times 10^{20} \mathrm{ergs}\right)\end{array}$} \\
\hline $\begin{array}{c}\text { Shallow }\left(N_{8}\right) \\
\text { l. }\end{array}$ & $\begin{array}{c}\text { Intermediate } \\
\qquad\left(N_{i}\right) \\
2 .\end{array}$ & & $\begin{array}{c}\text { Shallow }\left(E_{\kappa}\right) \\
4 .\end{array}$ & $\begin{array}{c}\text { Intermediate } \\
\qquad\left(E_{i}\right) \\
5 .\end{array}$ \\
\hline 0.0167 & - & 8.6 & 1182.00 & - \\
\hline 0.0333 & - & 8.3 & 592.00 & - \\
\hline 0.0333 & 一 & 8.0 & 210.00 & - \\
\hline 0.0667 & 0.0167 & 7.7 & 149.30 & 37.39 \\
\hline 0.1334 & - & 7.6 & 211.40 & - \\
\hline 0.0667 & 0.0333 & 7.5 & 74.80 & 37.36 \\
\hline 0.0333 & - & 7.4 & 26.45 & - \\
\hline 0.0833 & 0.0167 & 7.3 & 46.10 & 9.30 \\
\hline 0.0667 & 0.0167 & 7.2 & 26.54 & 6.60 \\
\hline 0.0500 & 0.0167 & 7.1 & 14.45 & 4.70 \\
\hline 0.0667 & 0.1167 & 7.0 & 13.31 & 23.28 \\
\hline- & 0.0167 & 6.9 & - & 2.35 \\
\hline 0.0833 & - & 6.8 & 8.30 & - \\
\hline 0.1167 & 0.1500 & 6.7 & 8.20 & 10.62 \\
\hline 0.0167 & 0.0833 & 6.6 & 0.83 & 4.17 \\
\hline 0.1500 & 0.3167 & 6.5 & 5.32 & 11.24 \\
\hline 0.0167 & 0.0500 & 6.4 & 0.42 & 1.26 \\
\hline 0.2167 & 0.2167 & 6.3 & 3.86 & 3.86 \\
\hline 0.1000 & - & 6.2 & 1.26 & - \\
\hline 0.1834 & 0.0667 & 6.1 & 1.60 & 0.59 \\
\hline 0.3167 & 0.2344 & 6.0 & 1.99 & 1.47 \\
\hline 0.1334 & 0.0500 & 5.9 & 0.60 & 0.23 \\
\hline 0.2334 & 0.1167 & 5.8 & 0.72 & 0.36 \\
\hline 0.3000 & 0.4834 & 5.7 & 0.66 & 1.06 \\
\hline 0.2334 & 0.1334 & 5.6 & 0.37 & 0.21 \\
\hline 0.3334 & 0.4000 & 5.5 & 0.37 & 0.44 \\
\hline 0.5834 & 0.3500 & 5.4 & 0.46 & 0.28 \\
\hline 1.3669 & 0.2500 & 5.3 & 0.78 & 0.14 \\
\hline 3.6900 & 0.8330 & 5.2 & 1.47 & 0.33 \\
\hline 3.7600 & 1.0000 & 5.1 & 1.06 & 0.28 \\
\hline 2.6900 & 2.0700 & 5.0 & 0.54 & 0.41 \\
\hline
\end{tabular}




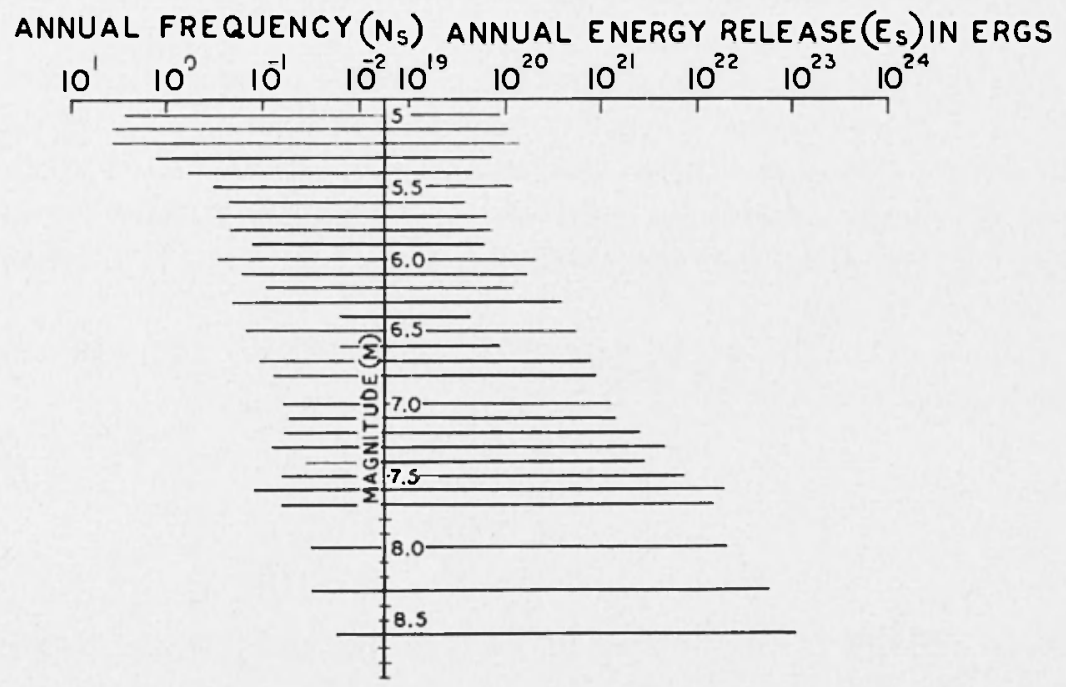

Fig. 1 - Frequency-energy distribution of Indian earthquakes against magnitude $M \geqslant 5$ for a period of 60 years, from 1910 to 1969 . The figure shows the distribution for shallow earthquakes.

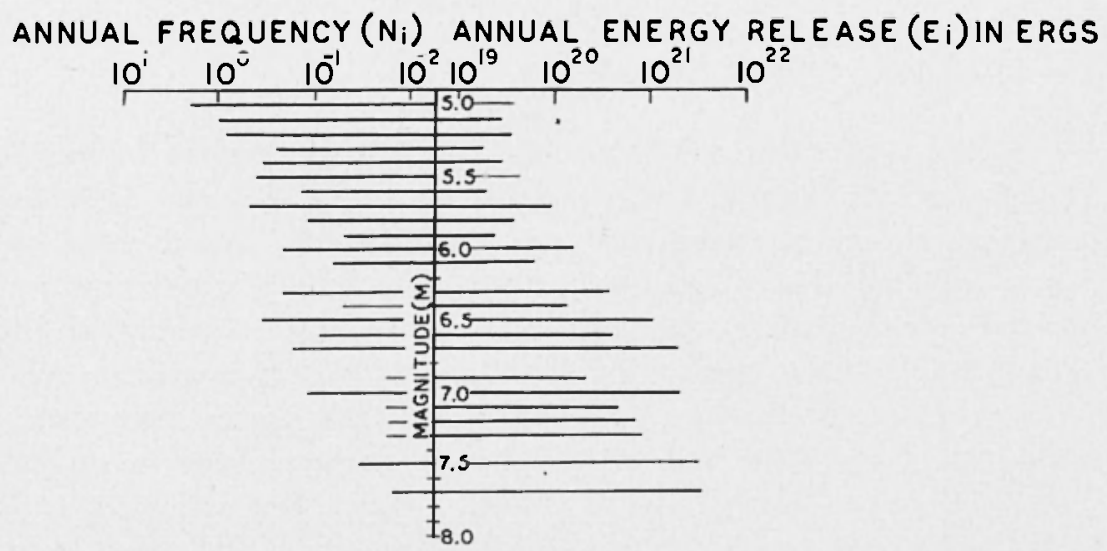

Fig. 2 - Frequency-energy distribution of Indian earthquakes against $M \geqslant 5$ for the same period of fig. 1 . The distribution is for intermediate earthquakes. 
the slope of $N$ changes from -0.4 to -1.5 . Hence, when the values of $B$ are 1.4 (approximately) to 1.5 and $b 1.4$ to 1.5 then the shape of figures 1 and 2 becomes parallelogram. For all other values of $b$ the general shape of figures 1 and 2 is quadrilateral tending to a triangle for small values of $b$. These observations may be interpreted in support of energy magnitude relations of Gutenberg-Richter (6) and Bath (1) where they have used the upper limit of the slope of frequency magnitude relation.

These relations can be expressed mathematically by combining the equations [2] and [3] in the form

where

$$
N(E)=C . E .^{-(b / B) \cdot 1}
$$

$$
C=\frac{10(a+A b / B)}{B \operatorname{in} 10}
$$

where $N(E) d E$ is the number of earthquakes with energy between $E$ and $E+d E$.

Here it may be mentioned that in U.S.S.R. the frequency-energy relation is used in the form

where

$$
\log n(K)-C-\nu K
$$

$$
K=\log E \quad \text { and } \boldsymbol{\nu}=b / B
$$

which is similar to relation [4].

\section{4. - Secular energy release}

In the years 1913, 1919 and 1953 the energy released by earthquakes was less than $10^{19}$ ergs and in the years 1934 and 1950 the maximum energy exceeding $10^{24}$ ergs was released. The average annual energy released by shallow earthquakes is $2.58 \times 10^{23}$ ergs and for the intermediate earthquakes $1.57 \times 10^{22}$ ergs respectively; the annual total release being $2.74 \times 10^{23}$ ergs. There are only eight years in which the energy release was more than the average energy release per year. The ratio of the average energy release in shallow and intermediate earthquakes is 16.5:1. Gutenberg and Richter $\left(^{5}\right)$ have shown that ratio for the shallow intermediate and deep earthquakes is $31: 4: 1$.

Each plotted points in figures 3 and 4 represents cumulative energy released by earthquakes since the beginning of 1910 until the 


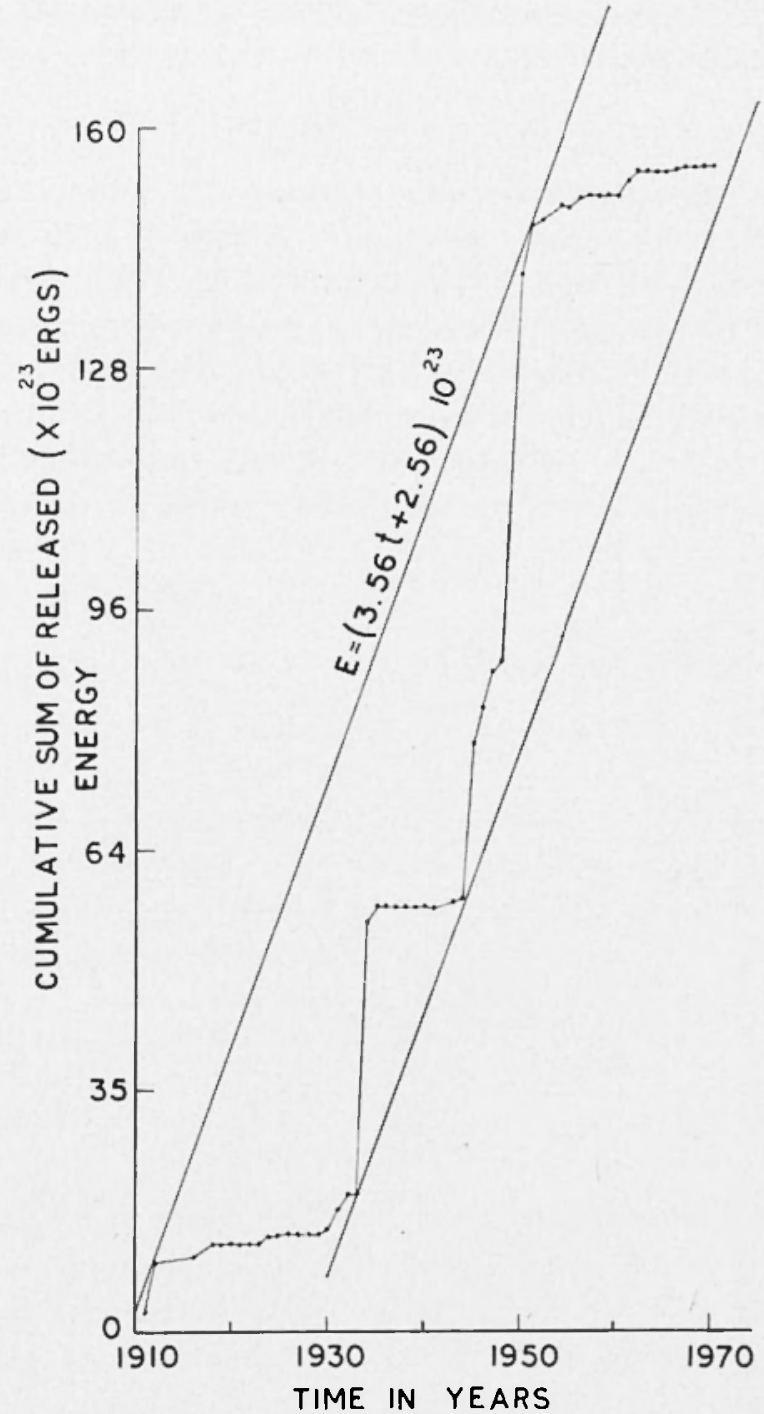

Fig. 3 - Cumulative sum of annual energy plotted against time for the same period of figs 1,2. The figure is a plot of shallow earthquakes.

end of 1969 , for a period of 60 years. The points are bounded in between parallel straight lines of which the upper line in fig. 3 is expressed for shallow earthquakes.

$$
\sum E_{s}=(3.56 t+2.56) 10^{23} \mathrm{ergs}
$$


where $\Sigma E_{s}$ is cumulative energy for shallow earthquakes, and for intermediate earthquakes

$$
\sum E_{\mathfrak{\imath}}=(2.23 t+0.85) 10^{22} \mathrm{ergs}
$$

where $2 E_{t}$ is the cumulative sum of energy for intermediate earthquakes.

In equations [6] and [7] $t$ is counted from 1910. The distance between the two parallel lines in fig. 3 corresponds to about $2 \times 10^{24}$ ergs which is very close to the energy of the largest conceivable earthquakes. Similarly in fig. 4 the distance between the two parallel lines corresponds to $1.81 \times 10^{23} \mathrm{ergs}$ which is very close to the largest intermediate shocks observed in the past 60 years.

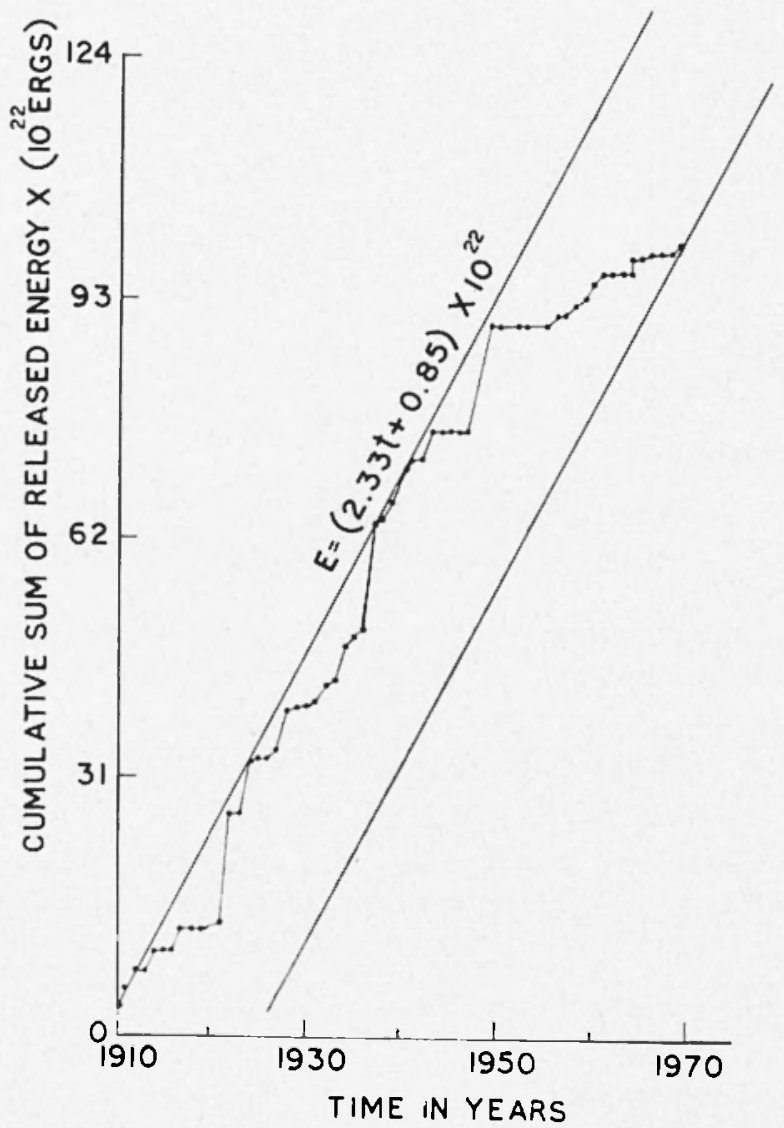

Fig. 4 - See the caption of fig. 3. The plot is for intermediate earthquakes. 
The slope in equations [6] and [7] gives approximately the rate of accumulation of energy in the crust and in the upper mantle upto a depth of about $300 \mathrm{~km}$, respectively.

Similar study carried out by Tsuboi $\left({ }^{9}\right)$ shows that the rate of accumulation of energy in Japan is $2.24 \times 10^{23}$ ergs per year and this rate of energy accumulation is 2.5 times higher than the rate of accumulation arrived at here which, after normalising in area, comes to $0.89 \times 10^{23}$ ergs per year. These interpretation of secular seismic energy release is quite in line with the observations of Bath and Duda $\left({ }^{2}\right)$. The rate of energy accumulation for shallow and intermediate earthquakes is always greater than the average energy release in these shocks and at the most they may be equal.

Distribution of number of earthquakes having $M \geqslant 5.3$ with depth is shown below in TaBLE 2 .

Depth range in kms. $0-50 \quad 50-100 \quad 100-150 \quad 150-200 \quad 200-250 \quad 250-300$ $\begin{array}{lllllll}\text { Number of shocks. } & 279 & 51 & 35 & 39 & 76 & 1\end{array}$

The distribution of earthquakes does show a maximum at a depth of $200-250 \mathrm{kms}$ which is in agreement with Ritsema's $\left({ }^{8}\right)$ second maximum and also agrees with Gutenberg-Richter's (1) minimum in the depth range of $250-300 \mathrm{kms}$.

\section{5. - Conclusions}

1) Frequency-magnitude and energy-magnitude distribution of shallow and intermediate earthquakes shown in figures 1 and 2 show logarithmic dependence of $N$ and $E$ on $M$ and relation between $N$ and $E$ may be written in the form $N(E)=C . E .^{-(b / B)-1}$

2) Secular studies of energy release clearly show that the average energy release is in general less than rate of accumulation of energy. It also follows from figures 3 and 4 that the maximum size of conceivable shallow earthquake is $M \simeq 8.6$ and of intermediate earthquake is $M \simeq 7.6$.

3) Distribution of number of earthquakes with depth shows a maxima at a depth of 200 to $250 \mathrm{kms}$ and a minima in the depth range of 250 to $300 \mathrm{kms}$. 


\section{ACKNOWLEDGEMENTS}

The authors are grateful to Profs. J. Singh, H. S. Rathor, R. K. Verma for discussions from time to time and for providing all the facilities to carry out the present work.

\section{REFERENCES}

(1) BAтн MI., 1958. - The energies of seismic body waves and surface waves. "Contributions in Geophysies in hon. of B. Gutenberg", 1-16.

(-) BATTI M. and DUdA S. J., 1964. - Earthquake volume, fault plane area, seismic energy, strain, deformation and related quantities. "Ann. di Geofis.", XVII, 353-368.

(3) Cilouina R. K. S. and Das U. C., 1971. - Preliminary report on Global seismicity, frequency energy distribution of earthquakes. "Pure and Applied Geophysics", 89, 98-108.

(4) Ciovinas R. K. S., 1970. - On the frequency magnitude relation $\log N=a-b M$. .Pure Appl. Geophys.", 81, 119-123.

(5) Gutenberg B, and Richter C. F., 1954, - Seismicity of the Earth and associated phenomena. "Princeton University Press".

(8) Gutenberg B. and Riciter C. F., 1956. - Magnitude and Energy of earthquakes, "Ann. di Geofis.", IX, 1-15.

(7) PAGE R., 1968. - Aftershocks and microaftershocks of the great Alaskan earthquake of 1964. "Bull. Seis. Soc. Am.", 58, 1131-1168.

(8) Ritsema A. R., 1954. - A statistical study of seismicity of the Earth. "Meteorol. and Geophys. Serv. Indonesia", 46, 41-46.

$\left({ }^{9}\right)$ Tsubor C., 1964. - Time rate of energy release by earthquakes in and near Japan. "Jl. Pliys. Earth", 12, 25-36.

(10) UTsU T., 1961. - A statistical study on the occurrence of aftershocks. "Geophys. Mag.", 30, 521-605. 